\title{
Diagramas de energia de orbitais em livros didáticos de Química Geral: uma análise sob o viés da semiótica Peirceana
}

\section{Orbital energy diagrams in general Chemistry textbooks: a Peircean semiotics analysis}

\author{
Evandro Rozentalski ${ }^{1}$ \\ http://orcid.org/0000-0002-3240-0602 \\ Paulo Alves Porto ${ }^{2}$ \\ https://orcid.org/0000-0002-5001-2742
}

\begin{abstract}
Resumo: Neste artigo foi analisado o emprego de diagramas de energia de orbitais em livros didáticos de Química Geral, utilizados no ensino universitário brasileiro ao longo do século XX. Para isso, 16 livros publicados entre 1950 e 2001 foram selecionados, e a semiótica peirceana foi utilizada como referencial de análise para o entendimento sobre diagramas. A análise revelou que o uso de diagramas de energia de orbitais ocorre em diferentes contextos de aplicação e com diferentes objetivos. Do ponto de vista da semiótica, os significados dos signos que compõem os diagramas, e as regras que orientam sua construção e operação, são previamente convencionados, fornecendo, assim, bases mínimas a respeito de como interpretá-los. Todavia, aspectos mais sutis se afastam dessa base mínima e podem acarretar interpretações não pretendidas por seus autores. Tais concepções alternativas podem ser superadas através de compreensões mais elaboradas sobre a natureza e o papel das representações no ensino, fundamentadas na semiótica Peirceana.
\end{abstract}

Palavras-chave: Ensino superior. Livro didático. Semiótica. Diagrama. Orbital.

\begin{abstract}
In this paper the use of orbital energy diagrams in General Chemistry textbooks used in Brazilian universities throughout the twentieth century was analyzed. Sixteen textbooks published between 1950 and 2001 were selected. C. S. Peirce's semiotics was chosen to analyze the use of energy diagrams in the textbooks. The analysis revealed that the use of orbital energy diagrams occurs in different contexts and with different goals. From a semiotic point of view, the meanings of the signs that make up the diagrams and the rules guiding their construction and operation are previously agreed, thus providing the foundations for their interpretation. However, more subtle aspects deviate from such foundations and may result in interpretations that were unintended by the textbooks authors. Such misconceptions may be overcome by means of more elaborate insights into the nature and the role of representations in teaching, such as those arising from Peircean semiotics.
\end{abstract}

Keywords: Higher education. Textbook. Semiotics. Diagrams. Orbital.

\footnotetext{
${ }^{1}$ Universidade de São Paulo (USP), Programa de Pós-Graduação Interunidades em Ensino de Ciências, São

Paulo, SP, Brasil. E-mail: <rozentalski@usp.br>.

${ }^{2}$ USP, Instituto de Química, São Paulo, SP, Brasil.
} 


\section{Introdução}

O emprego de diagramas no Ensino de Ciências tem sido investigado nas últimas décadas por uma diversidade de autores (BAKKER; HOFFMANN, 2005; CHITTLEBOROUGH; TREAGUST, 2008; GARCÍA; PERALES, 2006; KRAGTEN; ADMIRAAL; RIJLAARSDAM, 2013; LOMBARDI; CABALLERO, 2012; LOWE, 1987; SOLAZ-PORTOLÈS, 1996)chemicals. Em linhas gerais, tais autores compreendem que o papel dos diagramas é evidenciar relações entre conceitos, sendo, assim, ferramentas importantes para: tornar ideias abstratas mais concretas; integrar informações e facilitar o acesso a elas; pensar sobre ideias científicas e comunicá-las.

Diagramas se caracterizam por sua natureza complementar à linguagem puramente textual, de caráter serial, isto é, na qual as ideias seguem umas às outras de maneira regular, limitando a manipulação espacial. A linguagem textual é a preferida pelos professores para apresentar os conceitos e também como forma de registro avaliativo. Os diagramas, por sua vez, podem fornecer uma alternativa mais flexível em relação à linguagem textual, por facilitar a apreciação de relações não aparentes nessa última (GARCÍA; PERALES, 2006; LOWE, 1987, 1990).

Se, por um lado, os diagramas podem ser extremamente efetivos na comunicação de ideias científicas aos estudantes, por outro, podem levar a dificuldades na aprendizagem e mesmo a concepções alternativas sobre os conceitos científicos. Tais dificuldades decorrem, muitas vezes, do fato de que os estudantes não estão suficientemente cientes das regras e convenções utilizadas, do propósito e das limitações de cada diagrama, de como o diagrama incorpora as informações relacionadas ao domínio científico que representa, de qual a relação entre a representação e o representado (signo/objeto) exibida pelo diagrama, e de como o diagrama se articula com representações de outra natureza que têm em vista o mesmo objeto ou conjunto de objetos (CHITTLEBOROUGH; TREAGUST, 2008; GARCÍA; PERALES, 2006; KRAGTEN; ADMIRAAL; RIJLAARSDAM, 2013; LOMBARDI; CABALLERO, 2012; SOLAZ-PORTOLÈS, 1996)chemicals.

No Ensino de Química, um exemplo de tais representações pode ser dado pelos diagramas de energia de orbitais, os quais são utilizados no âmbito do ensino das teorias quânticas sobre a estrutura da matéria e ligação química. Nos referidos contextos, os diagramas ilustram visualmente o princípio de construção (ou princípio $A$ ufbau), que consiste em ir acrescentando os elétrons um a um nos níveis de energia a fim de se obter a configuração eletrônica de átomos, íons e moléculas. Embora se conceba, comumente, que o princípio de construção é um fundamento puramente teórico para a interpretação eletrônica da tabela periódica, seu papel na teoria de Bohr e nas teorias quânticas subsequentes foi o de integrar resultados empíricos às teorias da época. Tais desdobramentos permitiram interpretar espectros atômicos e, posteriormente, espectros moleculares no âmbito da teoria dos orbitais moleculares, e também proporcionaram o refinamento e a redefinição de conceitos como os de molécula e valência (PARK, 2001).

Do ponto de vista epistemológico, os diagramas de energia de orbitais podem ser compreendidos como ferramentas de raciocínio, pelo fato de possibilitarem informações sobre a ligação, energias e reatividade química. Por exemplo, a estabilidade de moléculas é uma das informações mais comuns extraídas dos diagramas de energia, dos quais se pode inferir também propriedades espectrais, geometrias moleculares e caminhos de reação. Ao destacar tais aspectos por meios relativamente simples, os diagramas contemplam propriedades físicas e químicas significativas da prática química. Os diagramas eliminam a necessidade de cálculos explícitos 
ao se basearem no ordenamento relativo das energias dos orbitais, permitindo racionalizar fatos químicos particulares e generalizá-los para outros casos (WOODY, 2000, 2004).

Apesar de seu amplo emprego, não se identificam, na pesquisa em Ensino de Química, investigações em torno dos diagramas de energia de orbitais, sob um ponto de vista filosófico e, principalmente, educacional. Assim, pretende-se avaliar o emprego de tais diagramas em livros didáticos, tendo em vista que os livros são importantes na tomada de decisões curriculares, na definição de conteúdos de ensino e de atividades desenvolvidas pelo professor em sala de aula (MATUS; BENARROCH; NAPPA, 2011).

A análise aqui proposta adotará como referencial a semiótica peirceana. Esta escolha é motivada, principalmente, pela constatação de que as pesquisas sobre diagramas citadas até aqui, em sua maioria, não empregam um referencial epistemológico explícito e robusto para as suas considerações a respeito da natureza e papel dos diagramas no ensino. Entendemos que o referencial escolhido pode abranger várias compreensões elencadas pela literatura, conferindolhes coerência e, também, aprofundando tais compreensões a respeito dos diagramas. Além disso, acrescenta-se que o referencial semiótico tem sido cada vez mais utilizado para investigar as representações empregadas para construir e comunicar o conhecimento químico no âmbito da Química e do Ensino de Química (ARAUJO NETO, 2012; GOIS; GIORDAN, 2007; SOUZA, 2012; WARTHA; REZENDE, 2011, 2015).

\section{Semiótica e a teoria geral dos signos}

Questões relativas à representação têm sido enriquecidas com abordagens provenientes da Semiótica. Neste trabalho, adotamos o referencial desenvolvido por Charles S. Peirce (1839-1914), um dos pioneiros das teorias semióticas modernas. Peirce concebeu a Semiótica no contexto de um amplo sistema filosófico, do qual iremos nos ater a somente uma parte: a teoria geral dos signos.

O processo de construção de significados na semiótica peirceana envolve sempre três componentes: objeto, signo e interpretante. O objeto pode ser classificado em objeto imediato e objeto dinâmico: o primeiro é representado pelo signo, o que resulta, por consequência, em uma representação incompleta e somente de certos aspectos do objeto; o segundo é o objeto em sua totalidade, o qual, por sua própria natureza, o signo não pode exprimir, ou seria idêntico ao próprio objeto, e não sua representação (PEIRCE, 1972). No âmbito de investigações da Natureza, o objeto dinâmico pode ser considerado como a realidade em toda a sua complexidade, de maneira que a conhecemos apenas por meio de manifestações de suas qualidades, as quais constituem os objetos imediatos para o cientista (SOUZA, 2012). Peirce (1972, p. 95) ainda esclarece que o objeto pode ser "perceptível, apenas imaginável ou mesmo insuscetível de ser imaginado em um determinado sentido".

Por sua vez, o signo é aquilo que está no lugar de um objeto ou vários objetos, sendo o veículo para comunicar à mente algo do exterior e transmitir significados (SANTAELLA, 1994, 2008). É pelo signo e por meio dele que conhecemos algo, a ponto de Peirce (1972, p. 143) sustentar que "todo nosso pensamento e conhecimento se dá por meio de signos". O signo só pode representar o objeto de certo modo e numa certa capacidade. A incompletude do signo, que representa apenas alguns aspectos do objeto dinâmico, implica que ele sempre está em falta com esse objeto. Essa deficiência do signo gera, como consequência, a mútua complementaridade 
dos signos. Tendo em vista um mesmo objeto ou fenômeno, podemos representá-lo através de diversos signos, cada qual privilegiando certos aspectos em detrimento de outros.

Finalmente, o signo dá origem (ou pode dar origem) a um interpretante, sendo que este termo não deve ser confundido com o intérprete do signo, mas se refere ao processo relacional que se gera na mente do intérprete (SANTAELLA, 2008). O interpretante pode ser entendido não somente como um pensamento, "mas uma ação ou uma experiência", ou mesmo "mera qualidade de sentimento” (PEIRCE, 1972, p. 142). Como esclarece Peirce (1972), o interpretante é criado pelo signo, mas também é, de modo mediado e relativo, criado pelo objeto do signo. $\mathrm{O}$ signo atua como mediador entre objeto e interpretante, estabelecendo-se uma relação triádica entre esses elementos. O processo de significação (semiose) é de natureza ininterrupta, pois, como a completude do signo é inatingível, a natureza dos interpretantes será sempre provisória. Cada interpretante gerado será um novo signo e, portanto, capaz de gerar outros interpretantes, evidenciando que a semiose, uma vez iniciada na mente do intérprete, pode prosseguir indefinidamente.

\section{A classificação dos signos: ícones, índices e símbolos}

Como destaca Queiroz (2007), a classificação dos signos foi aprimorada durante toda a vida de Peirce, e permanece até hoje em processo de reelaboração por semioticistas e pesquisadores de áreas afins. Neste trabalho, nos deteremos na classificação proposta por Peirce (1972) conforme a relação do signo com o objeto, podendo assim colocar em discussão o estatuto ontológico do objeto representado pelo signo, bem como o alcance epistemológico dessa relação. Tal classificação resulta em três categorias: ícone, índice e símbolo.

Os ícones representam por similaridade com o seu objeto e podem ser classificados em imagem, diagrama e metáfora. A imagem representa por similaridade no nível da aparência; o diagrama, por similaridade no nível das relaçôes; e a metáfora, por similaridade no nível do significado (SANTAELLA; NÖTH, 2008). A capacidade referencial de um ícone reside em poder ter alguma semelhança com as qualidades do seu objeto. Essa potencialidade, expressa pelo poder ter, revela um grau de ambiguidade do ícone, pois sua referencialidade se apresenta como uma sugestão (SANTAELLA, 2010). Portanto, não há uma conexão existencial obrigatória entre ícone e objeto: um ícone ainda seria significativo mesmo que seu objeto não existisse em um sentido concreto (PEIRCE, 1972). Os diagramas, em particular, serão abordados com mais detalhes na próxima seção.

A segunda classe de signo, o índice, apresenta uma relação de existência ou de correspondência de fato com o seu objeto, de maneira a chamar a atenção do intérprete, visando alertá-lo e conduzi-lo diretamente ao seu objeto (SANTAELLA, 2008). Signos de natureza indicial se caracterizam por se referirem a individuais ou singulares; e são inequívocos quanto ao objeto que eles apontam (PEIRCE, 1972). Uma fotografia constitui um exemplo de índice. Sua conexão com o objeto é de natureza existencial: a conexão de fato entre signo e objeto ocorre pela interação da luz refletida pelo objeto com a película sensível (o filme fotográfico), conduzindo ao registro, sob certos aspectos, do objeto. Caso não houvesse uma conexão física, o signo perderia sua natureza indicial, o que implica que seu objeto é necessariamente um existente concreto.

A terceira categoria de signo, o símbolo, é entendido como "um signo cuja virtude está na generalidade da lei, regra, hábito ou convenção de que ele é portador e a função como signo 
dependerá precisamente dessa lei ou regra que determinará seu interpretante" (SANTAELLA, 2008, p. 132). Nesse sentido, o símbolo constitui sua natureza por meio de uma conexão com o interpretante que deve estar previamente estabelecida no intérprete, seja como uma lei, regra ou hábito (PEIRCE, 1972; SANTAELLA, 1994). As palavras de um sistema linguístico são exemplos de símbolos, pois se relacionam com seus objetos simbolicamente através de convenções sociais, culturais e históricas recebidas a priori pelos intérpretes, isto é, as palavras só se tornam signos simbólicos quando os intérpretes são levados pelas convenções ou hábitos a interpretar de certo modo seus significados.

Por fim, é preciso ressaltar que um signo "vem sempre com misturas de caracteres icônicos, indiciais e simbólicos. Nenhum signo atual aparece em estado puro" (SANTAELLA, 2008, p. 27). Isso não torna menos útil a classificação apresentada para os signos, pois é possível inferir que um ou outro caráter, isto é, icônico, indicial ou simbólico, seja predominante em determinado signo por meio da comparação entre os signos investigados.

\section{Diagramas: signos que representam relações}

Na semiótica peirceana, diagramas são considerados importantes não apenas como meio de representar, mas, fundamentalmente, meios de pensar, compreender e raciocinar (BAKKER; HOFFMANN, 2005). Eles representam seus objetos através da similaridade nas relações, o que faz deles ícones. A natureza icônica dos diagramas deve ser compreendida para além da compreensão trivial de um ícone como signo que se refere ao seu objeto por virtude de similaridade, mas também por sua operacionalidade: por meio da observação ou manipulação direta do diagrama, outras características a respeito do objeto podem ser descobertas, as quais não foram necessárias para determinar a sua construção. É justamente essa propriedade de possibilitar aprendizado adicional que distingue os ícones dos signos simbólicos e indiciais puros (STJERNFELT, 2000). Nesse contexto, deixamos de considerar simples qualidades, cores, formas, etc. do objeto (compreensão ampla de ícone) e passamos a considerar as relações entre as partes do objeto (diagramas como ícones operacionais).

Todavia, para se constituir como um diagrama, um signo necessita, também, estabelecer previamente tanto as convenções envolvidas em sua construção quanto suas regras de operação, uma manifestação tipicamente simbólica. Isso implica na determinação de seu interpretante, que explicita previamente como o signo e seus elementos devem ser interpretados. Assim, conforme a particularidade das convenções e regras envolvidas, modos muitos diferentes de interpretação são possíveis para os diagramas. O que se observa, então, é a dupla determinação dos diagramas: icônica e simbólica (STJERNFELT, 2000). Essa compreensão não exclui a possibilidade da incorporação de aspectos indiciais aos diagramas, mas enfatiza seus aspectos essenciais.

Para exemplificar tais considerações, podemos mencionar os mapas, diagramas que são representações visuais de regiões geográficas. Os mapas são construídos tendo em vista um conjunto de convenções e regras de operação: cores, números e outros símbolos possuem significados particulares, que são explicitados por meio de legendas descritivas; assim como a escala do mapa, que baliza as considerações a serem feitas, sendo, em alguma medida, uma regra para operar sobre o mapa. Embora proporcionem uma série de informações iniciais aos leitores, os mapas não explicitam todas as informações passíveis de serem extraídas, de modo que a partir deles podemos encontrar uma rota entre duas localidades ou reconhecer a forma das 
paisagens, por exemplo. Ou seja, o diagrama nos revela informações que não foram necessárias para sua construção. Naturalmente, diferentes mapas podem nos trazer diferentes informações, conforme as características que definem a intenção de cada um.

Tendo delineado a semiótica peirceana como referencial, detalharemos os critérios de seleção, sistematização e análise dos diagramas de orbitais em livros didáticos de química geral, conforme a metodologia descrita a seguir.

\section{Metodologia}

A seleção dos livros de Química Geral utilizados ao longo do século XX no ensino universitário brasileiro se baseou no trabalho de Souza e Porto (2012). Esses autores adotaram como critério de seleção a presença simultânea nas seguintes bases de dados: os catálogos das bibliotecas da Universidade de São Paulo (USP), da Universidade Federal do Rio de Janeiro (UFRJ), e do site Estante Virtual, acervo que reúne sebos de todo o Brasil. As duas Universidades foram escolhidas por serem pioneiras no ensino universitário de Química no Brasil, enquanto que a presença em sebos é um indício da difusão das obras no país. Com esses critérios, se chegou a uma relação de 31 livros didáticos de Química Geral. Desse total, selecionamos apenas os livros que discutem o conceito de orbital, observando que isso ocorreu a partir de 1950 - resultando então em uma amostra de 16 livros que foi investigada. Na discussão que se segue, foram utilizadas letras maiúsculas, em negrito, para identificar cada um dos livros. A correspondência entre esse código e os respectivos livros é apresentada no Anexo A.

No que diz respeito à sistematização e análise dos dados, esta investigação se caracteriza por ser de natureza qualitativa, em que os referenciais apresentados até aqui proporcionam critérios para selecionar, organizar e interpretar aspectos relevantes a respeito dos diagramas de energia de orbitais presentes nos livros escolhidos (BOGDAN; BIKLEN, 1994).

Embora nosso interesse resida nos diagramas de energia de orbitais, empreendemos, inicialmente, uma caracterização das obras através da leitura de seus capítulos de apresentação e prefácios, com o intuito de identificar o público ao qual o livro se destina, objetivos didático-pedagógicos e outras informações que pudessem influenciar diretamente ou indiretamente na forma de apresentação dos diagramas de energia. O reconhecimento de tais informações permite compreender, em termos mais amplos, o emprego dado pelos livros didáticos aos diagramas de energia.

Ainda sob uma perspectiva panorâmica, efetuamos uma leitura rápida de toda a extensão da obra para identificar em quais capítulos os diagramas de energia são introduzidos, explicados e utilizados. Após isso, nossa análise se deteve, principalmente, nos capítulos em que eles são introduzidos e explicados pela primeira vez, pois em tais contextos era possível observar maior riqueza de detalhes. Ainda assim, sempre que se mostrou necessário, recorremos a capítulos posteriores para complementar nossas considerações.

Num segundo momento, buscamos caracterizar como os diagramas de energia de orbitais são apresentados pelos livros, em especial, tendo vista os seguintes critérios: importância atribuída a eles; abordagem adotada; em quais contextos são utilizados e de que forma. Em paralelo à caracterização, realizamos análises dos diagramas de acordo com a compreensão peirceana, fundamentada na classificação dos signos em símbolo, ícone e índice. Quando pertinentes, 
compreensões mais amplas sobre os signos, em especial, a tríade objeto-signo-interpretante, também foram incorporadas às análises.

\section{Resultados e Discussão}

\section{Uma visão geral dos diagramas de energia}

Os diagramas de energia de orbitais foram observados em 13 dos 16 livros que discutem o conceito de orbital selecionados nesta investigação, não sendo exibidos apenas nos livros J, $\mathbf{M}$ e $\mathbf{O}$. Os diagramas são introduz̨idos e discutidos pela primeira vez em capitulos destinados à estrutura da matéria, em especial na apresentação mecânico-quântica do átomo. Os diagramas aparecem novamente nos capítulos sobre a ligação química - em especial, no âmbito da hibridização de orbitais, e na teoria de orbitais moleculares, em que os diagramas de energia de espécies atômicas subsidiam a construção dos diagramas de orbitais moleculares. Nesse contexto, os diagramas de energia não recebem considerações tão aprofundadas como em capítulos iniciais, mas seu emprego subsidia uma série de explicações, como veremos mais adiante.

A abordagem adotada pelos livros para os diagramas de energia é essencialmente qualitativa, não se especificando, por exemplo: os valores numéricos das energias; sua ordem de grandeza; que os níveis são convencionalmente considerados menores que zero (valores negativos de energia) quando $\mathrm{n}<\infty$. O objetivo principal dos diagramas é apresentar o ordenamento relativo ou qualitativo dos níveis de energia dos orbitais, tendo como referência um eixo vertical que aponta em direção ao aumento de energia.

A natureza qualitativa dos diagramas pode ser interpretada dentro de um contexto mais amplo, fruto da abordagem adotada nos livros didáticos para a mecânica quântica e também tendo em vista o público ao qual se dirigiam. Quase a totalidade dos livros (15 de 16 obras) esclarece em seus prefácios que as obras são dirigidas a cursos introdutórios de Química, voltados a estudantes de Química ou áreas correlatas, ingressantes no primeiro ano do curso universitário. Desse grupo, apenas o livro $\mathbf{F}$ exige conhecimentos anteriores em cálculo diferencial e integral dos estudantes. A não exigência de conhecimento prévio sobre cálculo diferencial e integral nos demais livros resulta na adoção de uma abordagem qualitativa para a mecânica quântica e, em consequência, também para os diagramas de energia. Mesmo no único livro que exige tais conhecimentos, a abordagem não se distingue substancialmente daquela encontrada nos demais.

Assim, os livros podem apresentar algumas equações matemáticas da mecânica quântica, mas não aprofundam o formalismo matemático no sentido de explicitar como obtê-las, operar com elas e empregá-las em explicações. O emprego dos diagramas de energia tem como um dos seus objetivos eliminar a necessidade de cálculos explícitos, amparando-se no fato que tais representações requerem, como veremos mais adiante, o estabelecimento de um conjunto de convenções e regras para a sua manipulação que são mais simples se comparadas às equações matemáticas. Além disso, as equações matemáticas primam pelo rigor quantitativo - isto é, seu uso visa obter dados passíveis de serem comparados, por exemplo, com dados experimentais; enquanto o uso de diagramas objetiva explicitar relações de cunho qualitativo, em especial, as diferenças de energia entre os orbitais. 


\section{Estabelecendo convenções e regras para os diagramas}

O que se verifica nos livros de Química Geral é o estabelecimento de convenções e regras de operação mínimas em torno dos diagramas de energia, o que é feito antes da apresentação dos diagramas, ocorrendo, primeiramente, no âmbito da discussão dos números quânticos.

Em geral, os livros analisados introduzem primeiro o que podemos denominar de configuração eletrônica parcial do átomo ou íon, fundamentada somente nos dois primeiros números quânticos: n (número quântico principal) e $\ell$ (número quântico do momento angular). Essa configuração eletrônica é expressa por três elementos: um número natural, que varia 1 a $\infty$, referente ao número quântico principal $n$ que designa o nível de energia (quanto maior o valor de $n$, maior a energia); seguido por uma letra, comumente $s, p, d$ ou $f$, que designa um subnível de energia do nível principal $n$ e que se refere ao número quântico de momento angular $\ell$; e, por fim, um número sobrescrito a essa letra, o qual expressa o número de elétrons presentes no subnível. Essa configuração não explicita a disposição dos elétrons de acordo com número quântico magnético $m_{\ell}$ e também não evidencia se os elétrons estão emparelhados ou desemparelhados, o que é caracterizado pelo número quântico de spin $\mathrm{m}_{\mathrm{s}}$.

Com o intuito de contemplar os números quânticos $\mathrm{m}_{\ell}$ e $\mathrm{m}_{\mathrm{s}}$, uma parcela dos livros didáticos (7 de 13 obras que apresentam os diagramas de energia) recorrem ao que chamam simplesmente de diagramas de orbitais (Figura 1a). A importância de tais diagramas é justificada pelos livros de Química Geral, ainda que não explicitamente em todos os casos, pelo fato de ilustrarem o arranjo dos elétrons nos átomos e íons, principalmente os de maior energia, os elétrons de valência. Estes são de suma importância na formação da ligação química, discutida posteriormente pelos livros.

Figura 1. Exemplos de diagramas de orbitais (a) e de energia (b) em livros de Química Geral

(a)

\begin{tabular}{|c|c|c|c|c|c|c|c|}
\hline \multirow[t]{2}{*}{ Elemento } & \multirow[t]{2}{*}{$\begin{array}{l}\text { Total de } \\
\text { Elétrons }\end{array}$} & \multicolumn{6}{|c|}{ Diagrama de Orbitais } \\
\hline & & Is & $2 s$ & & $2 p$ & & 3s \\
\hline $\mathrm{Li}$ & 3 & $1 l$ & 1 & & & & \\
\hline $\mathrm{Be}$ & 4 & $1 l$ & 11 & & & & \\
\hline B & 5 & 11 & 11 & 1 & & & \\
\hline C & 6 & 11 & $1 l$ & 1 & 1 & & \\
\hline $\mathrm{N}$ & 7 & $1 l$ & $1 l$ & 1 & 1 & 1 & \\
\hline $\mathrm{Ne}$ & 10 & 11 & $1 \downarrow$ & $1 \downarrow$ & $1 \downarrow$ & 11 & \\
\hline $\mathrm{Na}$ & 11 & $1 l$ & $1 \downarrow$ & $1 l$ & 1 & $1 l$ & 1 \\
\hline
\end{tabular}

(b)

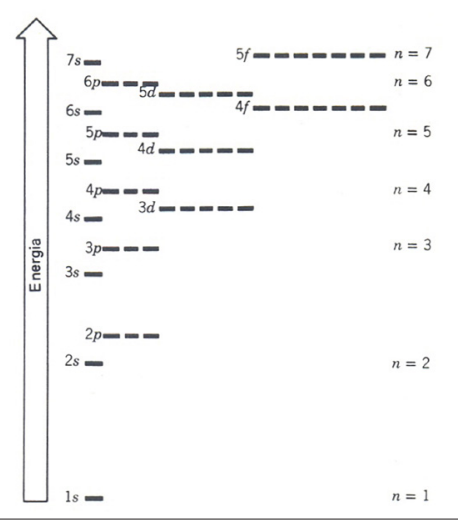

Fontes: (a) Brady e Humiston (1986); (b) Brown, Lemay Jr. e Bursten (1999).

Os elementos que constituem os signos "diagramas de orbitais" são convencionados de forma semelhante ao que é feito para os diagramas de energia. Em geral, se observa uma simples descrição dos signos, como no exemplo a seguir: 
Como geralmente interessa apenas o número de orbitais de uma subcamada, é conveniente representá-los por traço e indicar sua população por flechas com direções contrárias, para mostrar os dois possíveis spins (Secção 3.11). [...] Cada par de flechas representa um par eletrônico que ocupa aquele orbital particular; uma flecha isolada representa um elétron não-emparelhado em um orbital. (SIENKO; PLANE, 1977, p. 416).

A partir dos exemplos, podemos avaliar que as convenções comunicam previamente ao leitor os significados dos signos empregados na sua construção. Esses signos - como no caso das setas que tomam lugar dos elétrons, ou das linhas horizontais que tomam lugar dos orbitais - não se associam aos seus objetos por similaridade na aparência, mas por convenção. No âmbito dos livros investigados, todos convencionam o significado dos signos que compõem os diagramas, caracterizando sua manifestação simbólica. A associação simbólica entre signo e objeto permite que o tipo de símbolo empregado possa ser diferente, desde que seja estabelecido previamente o significado do símbolo utilizado. De fato, embora as linhas horizontais ou quadrados sejam utilizados pela maioria dos livros investigados, é possível constatar outros símbolos que tomam o lugar do orbital, como, por exemplo, parênteses e circunferências. Não comunicar previamente o significado de um signo simbólico, bem como qual é sua relação com o objeto, que nesse caso não está no nível de similaridade na aparência, pode resultar em compreensões não pretendidas para o signo.

As obras ainda apresentam regras de operação sobre os diagramas, como a regra de Hund (os orbitais de mesma energia devem ser, primeiramente, semi-preenchidos, e somente então totalmente preenchidos) e o princípio de exclusão de Pauli (não mais que dois elétrons, com spins opostos, podem ocupar um mesmo orbital). Tais regras se caracterizam como subsídios para guiar a operação sobre os diagramas, pois o preenchimento de um orbital, por exemplo, com dois elétrons de mesmo spin, embora possível graficamente, estaria em discordância com os conhecimentos teóricos e experimentais. Ainda que estas regras não sejam de mesma natureza que as convenções discutidas anteriormente, elas também devem ser previamente comunicadas aos estudantes.

Finalmente, os diagramas de energia são introduzidos e incluem muitos dos elementos representacionais contidos nos diagramas de orbitais. Entretanto, enquanto nestes últimos os diferentes orbitais são dispostos em paralelo, sem evidenciar que se referem a diferentes níveis de energia (Figura 1a), nos diagramas de energia há distinção entre os níveis de energia por meio de sua disposição conforme um eixo vertical, o qual aponta o sentido em que a energia aumenta (Figura 1b). Apesar disso, ao serem introduzidos os diagramas de energia, não ocorre, em geral, a explicitação do significado do eixo de energia, um signo não presente nos diagramas de orbitais, assim como da disposição dos orbitais na vertical, conforme suas diferentes energias. Esses novos elementos sígnicos são considerados autoevidentes quanto aos seus significados nos livros analisados.

Como destacado na introdução deste artigo, os diagramas de energia foram pensados e empregados inicialmente para ilustrar o princípio de construção (ou princípio $A$ ufbau). Desse modo, seria razoável esperar que os diagramas de energia fossem utilizados amplamente pelos livros tendo em vista esse fim. Contudo, poucos são os livros $(\mathbf{A}, \mathbf{D}, \mathbf{K}$ e $\mathbf{L})$ que o fazem: a maioria $(\mathbf{B}, \mathbf{C}, \mathbf{E}, \mathbf{F}, \mathbf{G}, \mathbf{H}, \mathbf{I}, \mathbf{N}$ e $\mathbf{P})$ se restringe, inicialmente, a ilustrar os diferentes níveis de 
energia dos orbitais, sem representar os elétrons como setas. Como visto, o papel de ilustrar o princípio de construção é assumido pelos diagramas de orbitais, em geral apresentados antes dos diagramas de energia.

De acordo com a perspectiva semiótica da mútua complementaridade dos signos, ainda que haja um conjunto de aspectos em comum numa gama de representações, os poucos aspectos que distinguem uma representação da outra fazem com que cada uma delas tenha, preferencialmente, um emprego particular. Assim, os livros recorrem à representação que fornece mais facilmente a informação particular que lhes interessa comunicar: no caso da ilustração do princípio de construção, isso é feito por meio dos diagramas de orbitais que, diferentemente dos diagramas de energia, não recorrem a um eixo vertical de energia e não dispõem os orbitais de acordo com suas energias. No particular momento em que os autores dos livros estão interessados apenas na introdução do modelo mecânico-quântico para os átomos, os diagramas de orbitais são utilizados, visto ser seu objetivo fornecer o estado eletrônico de átomos ou íons. Em capítulos posteriores dos livros, como veremos mais adiante, os diagramas de energia são efetivamente empregados, em especial nos capítulos sobre a ligação química (Figura 2), tendo em vista o interesse em salientar as diferentes energias dos orbitais. Diante disso, deve-se tornar explícito no ensino que não se trata de "melhores" ou "piores" representações, mas que a adequação de cada uma depende do objetivo pretendido, e que as representações podem ser mutuamente complementares e proporcionar diferentes informações, cada qual à sua maneira, a respeito do objeto em estudo.

\section{As relações e operacionalidade dos diagramas}

Na seção anterior discutimos, principalmente, a manifestação simbólica dos diagramas, caracterizada por suas convenções e regras de operação. Porém, os diagramas se manifestam também como ícones que representam relações. Nos diagramas de orbitais, prioriza-se a representação da relação entre o orbital e o elétron, em que o primeiro é representado por uma linha horizontal ou retângulo, enquanto o segundo é representado por uma seta. Tal relação é articulada com o intuito de representar a configuração eletrônica de átomos e íons. Por sua vez, nos diagramas de energia, é estabelecida uma nova relação, a saber, de como se dá o ordenamento de energia entre esses diferentes orbitais. Introduz-se, aqui, uma nova qualidade para estabelecer essa relação: a energia associada a cada orbital que compõe o átomo.

Embora tenha sido previamente comunicado aos estudantes que o número quântico principal $n$ indica as energias dos orbitais, os diferentes subníveis de um mesmo nível podem ter diferentes energias, as quais não são representadas nos diagramas de orbitais. Nesse sentido, os diagramas de energia explicitam as energias dos subníveis de um nível particular e, principalmente, como se dá a relação (ordenamento) dessas energias com os demais níveis e subníveis. Além dos signos linhas e setas, acrescenta-se um novo signo: um eixo vertical, geralmente encimado por uma seta, que aponta o sentido crescente da energia e que estabelece sua relação com a representação dos orbitais na forma de quadrados ou linhas horizontais. As linhas horizontais, ao estabelecerem sua relação com o eixo vertical de energia crescente, sugerem valores determinados para as energias dos subníveis, ou seja, sua quantização.

Como destacam Bakker e Hoffmann (2005), apoiados na semiótica peirceana, conceitos abstratos ou gerais, como a ideia de uma energia associada aos orbitais, implicam que 
só podemos nos referir a eles por meio de signos e, por consequência, precisamos de signos para pensar sobre eles. Nesse caso, os objetos dos quais as representações tomam o lugar não necessitam de existência concreta, e podem ser apenas imagináveis (hipotéticos). Assim, um conceito abstrato, tal como a energia, torna-se "visível" nos signos e nos usos dados a eles. Quando direcionamos tais considerações aos diagramas de energia, observamos que não é um único elemento sígnico que representa a energia, por exemplo, a consideração apenas de uma linha horizontal, mas o conjunto deles, a saber, a disposição das linhas horizontais balizadas por um eixo vertical. É esse conjunto que nos informa as diferentes energias dos orbitais ou, mais precisamente, as energias relativas entre eles.

Os diagramas de energia, dada sua manifestação icônica, caracterizam-se também por sua operacionalidade nos livros investigados, pela qual seu emprego ou manipulação nos revelam novas informações, as quais não são dadas por suas convenções e regras de operação. Os próprios diagramas de orbitais, antes dos diagramas de energia, estabelecem convenções e regras de operações mínimas que permitem determinar, para cada átomo ou íon, seu arranjo de elétrons, possibilitando inferir sua reatividade química. Tais informações não são dadas a priori pelos diagramas, mas, ao contrário, são possíveis a posteriori, por meio de sua manipulação, tendo em vista um átomo ou íon específicos e seus elétrons correspondentes. Para além do que se apresenta no diagrama, em termos da distribuição dos elétrons, diferentes inferências podem ser feitas, por exemplo, a respeito da reatividade do referido átomo ou íon, gerando informações que não estão explícitas no diagrama. Tais inferências são possíveis a partir do que se conhece experimentalmente em relação à reatividade de átomos ou íons com distribuição eletrônica semelhante ou idêntica. Por exemplo, pode-se identificar, ao fim da distribuição eletrônica para uma dada espécie química, que seus orbitais de maior energia estão totalmente ocupados. Nesse caso, a inferência decorreria do que se observa a respeito da reatividade de outras espécies químicas que também possuem orbitais de maior energia totalmente preenchidos.

Ainda que tais considerações a respeito dos diagramas de orbitais sejam aplicáveis também aos diagramas de energia, a operacionalidade destes só é observada no âmbito dos capítulos sobre ligação química. Nesses capítulos, a manipulação dos diagramas de energia é central para o entendimento da hibridização dos orbitais, indicando que os orbitais híbridos formados possuem energias médias em relação aos orbitais que lhes deram origem, bem como destacando o arranjo dos elétrons resultante. Ao apresentar a teoria de orbitais moleculares (TOM), os diagramas de energia de espécies atômicas são a base para a construção dos diagramas de orbitais moleculares, permitindo identificar os novos arranjos eletrônicos e as novas ordenações relativas dos orbitais moleculares. Além disso, podemos observar, nos livros didáticos, a operação sobre os diagramas de energia no sentido de identificar a transição eletrônica entre diferentes orbitais, revelando qual elétron e quais orbitais estão envolvidos. Em cada um destes casos, informações particulares são proporcionadas pelos diagramas de energias, cada qual podendo ser apresentado com diferentes propósitos. A Figura 2 traz exemplos desses diferentes empregos dos diagramas de energia.

Essa diversidade de informações que podem ser reveladas pelos diagramas de energia corrobora a ideia de que são ferramentas de raciocinio, fornecendo informações sobre a energia, a reatividade e a ligação química (WOODY, 2000). Para se chegar a tais informações, há a necessidade de se construir os raciocínios que nos conduzem a elas. O raciocínio é realizado mediante a operação sobre os diagramas e na análise em torno do que se obtém após a operação. A análise 
vai além do diagrama, na medida em que recorre a conhecimentos teóricos e experimentais para realizar inferências. As informações obtidas a partir dos diagramas não são autoevidentes, mas são inferidas, de maneira que o emprego pleno dos diagramas requer a explicitação do que se pode fazer com eles: quais informações são passíveis de ser extraídas; em quais contextos as informações são pertinentes e em quais elas não são; como extrair essas informações; etc. Os livros de Química Geral procuram mostrar essas possibilidades através da aplicação dos diagramas de energia em diferentes contextos. Todavia, esse uso predominantemente tácito dos diagramas pode ocultar aspectos importantes que não são esclarecidos somente pela sua aplicação. Mais adiante, exemplificamos isso ao abordar as representações de orbitais vazios e orbitais cheios.

Figura 2. Diferentes empregos para os diagramas de energia

(a)

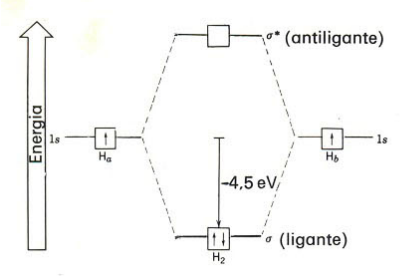

(b)

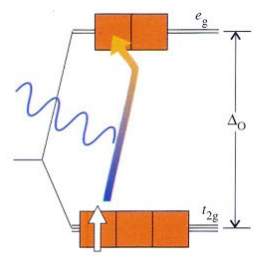

(c)

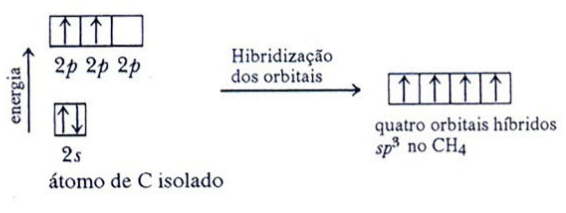

(a) explicar a formação da ligação química no âmbito da TOM; (b) explicar a transição eletrônica; (c) explicar a hibridização dos orbitais.

Fontes: (a) Slabaugh e Parsons (1977); (b) Atkins e Jones (2001); (c) Kotz e Treichel Jr. (1998).

Podemos observar, ainda, que os diagramas de energia nos livros de Química Geral se manifestam, em determinados contextos, como índices, em especial nas representações referentes às transições eletrônicas (Figura $2 \mathrm{~b}$ ). Metade dos livros investigados (A, C, E, F, H, L, $\mathbf{M}$ e N) utilizam os diagramas com essa finalidade em seus últimos capítulos, em particular, no âmbito da discussão dos metais de transição, com o intuito de explicar a diversidade de cores que seus compostos podem exibir. Notadamente, a discussão desse tópico não está entre os objetivos centrais dos livros de Química Geral. Em cursos de graduação em Química e áreas correlatas, bem como na prática química, os diagramas de energia são amplamente empregados no contexto das espectroscopias eletrônicas (ultravioleta e visível). Destaca-se que a utilização dos diagramas para identificar a transição eletrônica também ocorre na explicação da hibridização de orbitais, embora não seja o principal objetivo nesse contexto. No caso da representação da transição eletrônica, tal como a da Figura 2b, esta tem o objetivo de explicar um processo, os efeitos de um evento de natureza factual, pois indica que o elétron (objeto), ao absorver energia na forma de um fóton, "salta" de um orbital de menor energia para um de maior energia. A seta que parte do orbital de menor energia e aponta para o de maior energia, na Figura $2 \mathrm{~b}$, tem essa função indicial. 


\section{A equivalência ontológica entre orbitais vazios e orbitais cheios}

A característica dos diagramas de representar relações entre as partes do objeto (ou objetos) pode provocar ideias (interpretantes) não desejadas, quando não esclarecemos suficientemente os significados dos signos empregados e das relações representadas. Ao observarmos as Figuras 1 e 2, notamos a sugestão de duas ontologias distintas ou, em outros termos, a sugestão da existência de dois objetos aparentemente diferentes, dos quais as representações tomam lugar: o orbital, representado por um quadrado ou linha horizontal, e o elétron, representado por uma seta. Nesse contexto, os diagramas sugerem ao leitor a concepção de que orbitais vazios, representações sem o acréscimo de setas, são entidades preexistentes e, por consequência, reais.

Além disso, podemos observar o emprego corriqueiro e não problemático de orbitais vazios em diversos contextos nos quais se corrobora sua igualdade ontológica com os orbitais preenchidos. Ogilvie (1990) destaca que, na Química e em seu ensino, uma diversidade de fenômenos físicos e químicos tem sido explicada por meio de orbitais vazios, como, por exemplo, a estabilidade de compostos de transição em termos da doação- $\pi$ ou da retrodoação em orbitais d.

De maneira geral, poucos dos livros analisados $(\mathbf{E}, \mathbf{F}$ e $\mathbf{N})$ apresentam esclarecimentos quanto ao significado das representações dos orbitais vazios, e qual sua relação tanto com os orbitais preenchidos quanto com os elétrons. Conforme já mencionamos, em termos semióticos, um mesmo objeto pode ser representado por diferentes signos, assim como uma mesma representação pode se referir a diferentes objetos. Além disso, os objetos podem ser somente imagináveis (hipotéticos). Contudo, na ausência de esclarecimentos sobre o significado de certas representações, bem como sobre possíveis relações entre elas, é natural considerar que signos distintos se referem a objetos distintos. Ou seja, se os orbitais são representados por linhas horizontais ou quadrados, e os elétrons são representados por setas, haverá uma tendência a considerá-los como entidades distintas. Daí, a naturalização, isto é, o emprego não problemático, do conceito de orbital vazio se consolida, associado à concepção de que o orbital é uma entidade independente do elétron.

Essa questão se torna ainda mais complexa quando se observa que o objetivo dos livros de Química Geral, ao representar simbolicamente o orbital nos diagramas de energia, é salientar que, para cada orbital, há uma energia associada. Dessa maneira, as representações simbólicas de orbitais vazios sugerem também a existência de níveis de energia que são independentes do elétron. Diante disso, é importante esclarecer aos estudantes que, a partir de um mesmo objeto, por exemplo, o elétron, suas qualidades podem dar lugar a diferentes representações e serem articuladas entre si com uma dada finalidade. Nesse caso, o orbital visa destacar o comportamento espacial do elétron, ao qual se associa uma energia específica; e, ainda, orbitais vazios são representações que tomam lugar de estados potenciais do elétron, tendo em vista que signos não precisam se referir a existentes concretos, mas podem ser empregados para podermos pensar em possibilidades que se atualizam em certas condições.

\section{Conclusões e implicações}

Os livros de Química Geral do século XX investigados podem ser considerados representativos das compreensões partilhadas entre os químicos a respeito dos diagramas de energia, 
tendo sido divulgadas para diversas gerações de químicos e professores de Química brasileiros. Ainda que as obras investigadas tenham sido publicadas no século passado, os aspectos aqui apontados se revelam atuais, e podem fornecer reflexões quanto ao papel dos livros didáticos de Química Geral utilizados na atualidade, no que se refere à compreensão dos diagramas de energia por parte dos estudantes. Podem, também, proporcionar subsídios para a elaboração de estratégias para o ensino dos diagramas de energia, considerando sua importância, potencialidades e possíveis dificuldades inerentes ao seu emprego.

É possível concluir que as obras investigadas fornecem uma base mínima de informações a respeito de como interpretar os diagramas: as convenções e regras de operação sobre os diagramas são (ao menos em parte) explicitadas aos estudantes, e seu propósito é indicado e reforçado implicitamente através de sua aplicação.

Apesar disso, outros aspectos são pouco discutidos ou mesmo negligenciados pelos livros: as limitações dos diagramas não são apontadas aos estudantes, pois não se destaca que os diagramas visam representar um aspecto do objeto e, por consequência, fornecem informações parciais a seu respeito; os objetivos que se tem em vista quando são empregados os diagramas não são explicitados, recorrendo-se, apenas, a seu uso tácito; a relação entre representação (signo) e representado (objeto) não é esclarecida, podendo levar a interpretações sobre o signo não pretendidas pelos autores; não se empreende, em alguns momentos, a integração entre a fundamentação teórica e as representações que dela decorrem, o que pode conduzir a dificuldades para sua compreensão. Por fim, ao abordar as informações passíveis de serem obtidas pelo uso de diagramas somente por sua aplicação em alguns contextos, os livros incorrem no perigo de tomar tais informações como autoevidentes, e não como inferidas e construídas por raciocínios.

A respeito do referencial adotado nesta análise, a semiótica peirceana se revela como um fundamento teórico fecundo não apenas para os diagramas em particular, mas para representações utilizadas em química de maneira geral. A tríade objeto-signo-interpretante, a classificação básica dos signos em ícone, índice e símbolo, e a compreensão de diagramas oriunda da semiótica podem subsidiar pesquisas futuras e proporcionar compreensões mais sofisticadas sobre as representações químicas.

A compreensão do diagrama, bem como de qualquer representação, como tomando lugar do objeto apenas sob certos aspectos e, portanto, não sendo o próprio objeto, nos leva a discutir, no contexto do ensino, que não existe " $a$ " melhor representação, pois cada uma delas seleciona um aspecto particular do objeto, e um conjunto de representações fornece uma visão complementar a seu respeito. Nesse sentido, como destaca Souza (2012), a mútua complementaridade dos signos faz com que as habilidades de manejo e compreensão dos diversos signos empregados sejam cruciais para os que constroem o conhecimento químico e, principalmente, para os que ensinam esse conhecimento. Assim, devemos discutir os limites e possibilidades de cada representação, e as semelhanças e diferenças entre as representações de um mesmo objeto.

A análise também mostra que os signos empregados nos diagramas são necessários para tornar tangíveis conceitos abstratos, mas sua discussão explícita é necessária para que não sejam tomados como concretos, como no caso dos orbitais vazios. Assim, o estabelecimento prévio de convenções e regras de operação a respeito dos diagramas deve ser acompanhado de discussões do significado de tais representações, em especial, qual a relação entre signo e objeto, quais qualidades são selecionadas para a representação, como elas se relacionam entre si, e qual 
a finalidade da seleção de uma ou outra qualidade. Caso essas discussões estejam ausentes, ou não suficientemente detalhadas, podem levar ao desenvolvimento de concepções alternativas.

Esta investigação salienta a importância da discussão da natureza e do uso das representações no ensino, as quais, muitas vezes, são empregadas de modo não problemático. Embora a pesquisa em Ensino de Ciências tenha se debruçado, nas últimas décadas, sobre a questão das representações em geral, o papel dos diagramas, em geral, e dos diagramas de energia, em particular, ainda carecem de mais investigações no Ensino de Química. Assim sendo, propõe-se como perspectiva para futuras pesquisas um olhar para como os estudantes entendem os diagramas de energia - isto é, deslocar o foco dos livros didáticos, como foi feito no presente trabalho, para seus leitores, os aprendizes. Em termos semióticos, isso equivaleria a deslocarmos a análise dos signos presentes nos livros em direção aos interpretantes provocados por eles nos estudantes.

\section{Agradecimentos}

Os autores agradecem o apoio do Conselho Nacional de Desenvolvimento Científico e Tecnológico (CNPq, 304450/2014-6 e 307652/2017-3) e da Fundação de Amparo à Pesquisa do Estado de São Paulo (FAPESP, 2011/15295-0).

\section{Referências}

ARAUJO NETO, W. N. Estudos sobre a noção de representação estrutural na educação em química a partir da semiótica e da filosofia da química. Revista Virtual de Química, Niteroi, v. 4, n. 6, p. 719-738, 2012.

ATKINS, P. W.; JONES, L. Princípios de química: questionando a vida moderna e o meio ambiente. Porto Alegre: Bookmam, 2001.

BAKKER, A.; HOFFMANN, M. H. G. Diagrammatic reasoning as the basis for developing concepts: a semiotic analysis of students' learning about statistical distribution. Educational Studies in Mathematics, Dordrecht, v. 60, n. 3, p. 333-358, 2005.

BOGDAN, R.; BIKLEN, S. Investigação qualitativa em educação: uma introdução à teoria e aos métodos. Porto: Porto Editora, 1994.

BRADY, J. E.; HUMISTON, G. E. Química geral. Rio de Janeiro: LTC, 1986.

BROWN, T. L.; LEMAY JR., H. E.; BURSTEN, B. E. Química: ciência central. Rio de Janeiro: LTC, 1999.

CHITTLEBOROUGH, G.; TREAGUST, D. Correct interpretation of chemical diagrams requires transforming from one level of representation to another. Research in Science Education, Dordrecht, v. 38, n. 4, p. 463-482, 2008. 
GARCÍA, J. J. G.; PERALES, F. J. P. ¿Cómo usan los profesores de química las representaciones semióticas? Revista Electrónica de Enseñanza de las Ciencias, Vigo, v. 5 , n. 2, p. 247-259, 2006.

GOIS, J.; GIORDAN, M. Semiótica na química: a teoria dos signos de Peirce para compreender a representação. Química Nova na Escola, São Paulo, n. 7, p. 34-42, 2007. KOTZ, J. C.; TREICHEL JR., P. Química e reações químicas. Rio de Janeiro: LTC, 1998. KRAGTEN, M.; ADMIRAAL, W.; RIJLAARSDAM, G. Diagrammatic literacy in secondary science education. Research in Science Education, Dordrecht, v. 43, n. 5, p. 1785-1800, 2013.

LOMBARDI, G. L.; CABALLERO, C. S. El discurso multimodal de la química y el aprendizaje significativo de proposiciones. Investigações em Ensino de Ciências, Porto Alegre, v. 17, n. 3, p. 721-734, 2012.

LOWE, R. K. Diagram information and its organisation in memory: exploring the role of skill and experience. Research in Science Education, Dordrecht, v. 20, n. 1, p. 191-199, 1990.

LOWE, R. K. Drawing out ideas: a neglected role for scientific diagrams. Research in Science Education, Dordrecht, v. 17, n. 1, p. 56-66, 1987.

MATUS, L.; BENARROCH, A.; NAPPA, N. La modelización del enlace químico en libros de texto de distintos niveles educativos. Revista Electrónica de Enseñanza de las Ciencias, Vigo, v. 10, n. 1, p. 178-201, 2011.

OGILVIE, J. F. There are no such things as orbitals. Journal of Chemical Education, Easton, v. 67, n. 4, p. 280-289, 1990.

PARK, B. S. A principle written in diagrams: the Aufbau principle for molecules and its visual representations, 1927-1932. In: KLEIN, U. (Ed.). Tools and modes of representation in the laboratory sciences. Dordrecht: Kluwer, 2001. p. 179-198.

PEIRCE, C. S. Semiótica e filosofia. São Paulo: Cultrix, 1972.

QUEIROZ, J. Classificações de signos de C. S. Peirce: de "on the logic of science" ao "syllabus of certain topics of logic". Trans/Form/Ação, Marília, v. 30, n. 2, p. 179-195, 2007.

SANTAELLA, L. O que é semiótica. São Paulo: Brasiliense, 1994.

SANTAELLA, L. Semiótica aplicada. São Paulo: Cengage Learning, 2010.

SANTAELLA, L. A teoria geral dos signos: como as linguagens significam as coisas. São Paulo: Cengage Learning, 2008.

SANTAELLA, L.; NÖTH, W. Imagem: cognição, semiótica, mídia. São Paulo: Iluminuras, 2008.

SIENKO, M. J.; PLANE, R. A. Química. São Paulo: Nacional, 1968. 
SLABAUGH, W. H.; PARSONS, T. D. Química geral. Rio de Janeiro: LTC, 1977.

SOLAZ-PORTOLÈS, J. J. Diagramas: ¿ilustraciones eficaces en la instrucción en ciencias?

Educación Química, México, v. 7, n. 3, p. 145-149, 1996.

SOUZA, K. A. F. D. Estratégias de comunicação em química como índices

epistemológicos: análise semiótica das ilustrações presentes em livros didáticos ao longo do século XX. 2012. 189 f. Tese (Doutorado em Química) - Instituto de Química, Universidade de São Paulo, São Paulo, 2012.

SOUZA, K. A. F. D.; PORTO, P. A. Chemistry and chemical education through text and image: analysis of twentieth century textbooks used in Brazilian context. Science \& Education, Dordrecht, v. 21, n. 5, p. 705-727, 2012.

STJERNFELT, F. Diagrams as centerpiece of a Peircean epistemology. Transactions of the Charles S. Peirce Society, Indiana, v. 36, n. 3, p. 357-384, 2000.

WARTHA, E. J.; REZENDE, D. B. A elaboração conceitual em química orgânica na perspectiva da semiótica Peirceana. Ciência \& Educação, Bauru, v. 21, n. 1, p. 49-64, 2015.

WARTHA, E. J.; REZENDE, D. B. Os níveis de representação no ensino de química e as categorias da semiótica de Peirce. Investigações em Ensino de Ciências, Porto Alegre, v. 16, n. 2, p. 275-290, 2011.

WOODY, A. I. More telltale signs: what attention to representation reveals about scientific explanation. Philosophy of Science, Baltimore, v. 71, n. 5, p. 780-793, 2004.

WOODY, A. I. Putting quantum mechanics to work in chemistry: the power of diagrammatic representation. Philosophy of Science, Baltimore, v. 67, p. S612-S627, 2000. 
Rozentalski, E.; Porto, P. A.

Anexo A. Livros didáticos de química geral analisados neste artigo

A ATKINS, P. W.; JONES, L. Princípios de química: questionando a vida moderna e o meio ambiente. Porto Alegre: Bookmam, 2001.

B BRADY, J. E.; HUMISTON, G. E. Química Geral. Rio de Janeiro: LTC, 1986.

C BROWN, T. L.; LEMAY JR., H. E.; BURSTEN, B. E. Química: ciência central. Rio de Janeiro: LTC, 1999.

D HARDWICK, E. R. Química. São Paulo: Edgard Blücher, 1965.

E KOTZ, J. C.; TREICHEL JR., P. Química e reações químicas. Rio de Janeiro: LTC, 1998.

F MAHAN, B. H. Química: um curso universitário. São Paulo: Edgard Blucher, 1970.

G MASTERTON, W. L.; SLOWINSKI, E. J. Química geral superior. Rio de Janeiro: Interamericana, 1978.

H O'CONNOR, R. Fundamentos de química. São Paulo: Harper e Row do Brasil, 1977.

I OHLWEILER, O. A. Introdução à química geral. Porto Alegre: Globo, 1967.

J PARTINGTON, J. R. Quimica general e inorgánica. Madrid: Dossat, 1950.

K PAULING, L. Química geral. Rio de Janeiro: Ao Livro Técnico, 1967.

L PIMENTEL, G. C.; SPRATLEY, R. D. Química: um tratamento moderno. São Paulo: Edgard Blücher, 1974.

M QUAGLIANO, J. V.; VALLARINO, L. M. Química. Rio de Janeiro: Guanabara, 1979.

N RUSSELL, J. B. Química geral. São Paulo: McGraw-Hill do Brasil, 1981.

O SIENKO, M. J.; PLANE, R. A. Química. São Paulo: Nacional, 1968.

P SLABAUGH, W. H.; PARSONS, T. D. Química geral. Rio de Janeiro: LTC, 1977.

Artigo recebido em 24/04/2017. Aceito em 18/10/2017.

Contato: Universidade de São Paulo (USP), Instituto de Química, Av. Prof. Lineu Prestes, 748, Bloco 7 superior, sala 0761, São Paulo, SP, 05508-900, Brasil. 